\title{
Chemical compositions and antioxidant activity of Heracleum persicum essential oil
}

\author{
Maryam Gharachorloo $^{1 *}$, Masoud Honarvar' ${ }^{1}$, Shima Mardani² \\ ${ }^{1}$ Department of Food Science and Technology, Science and Research Branch, Islamic Azad University, Tehran, Iran, \\ ${ }^{2}$ Department of Chemical Engineering, Science and Research Branch, Islamic Azad University, Tehran, Iran
}

\begin{abstract}
In this study essential oil of the aerial parts of Heracleum persicum a spice widely used in Iran was isolated by conventional hydrodistillation (HD) and microwave-assisted hydrodistillation (MAHD) techniques. The extraction yield was determined and the chemical compositions of essential oils were identified by the application of gas chromatography/mass spectrometry (GC/MS). The antioxidant activity was determined by two different methods: 1,1-diphenyl-2-picrylhydrazyl (DPPH) free radical scavenging and oven test methods. Although the main compounds of essential oils by the both extraction methods were similar, the essential oil extracted by HD with lower extraction efficiency showed more diverse compounds. The evaluation of antioxidant activity of the essential oil measured by delay in sunflower oil oxidation indicated that the antioxidant activity was dependent on the concentration which increased when higher concentrations of the essential oils were applied. The results of DPPH radical assay also indicated that the percentage of inhibition increased with increasing of essential oil concentration and $\mathrm{IC}_{50}$ value for essential oil extracted by MAHD method was obtained $1.25 \mathrm{mg} / \mathrm{mL}$. Therefore the Heracleum persicum essential oil might be recommended for use as a flavoring agent and a source of natural antioxidants in functional foods, formulation of the supplements and in medicinal due to numerous pharmacological activities.
\end{abstract}

Keywords: Heracleum persicum/essential oil/chemical composition. Heracleum persicum/functional properties. Heracleum persicum/antioxidant activity.

\section{INTRODUCTION}

Heracleum persicum is a flowering plant and native to Iran that commonly known as "Golpar". It belongs to Apiaceae family in the order of Apiales that contains about 300 genera and more than 3000 species. Heracleum species probably originates from the Middle East, somewhere south of Caucasian, but has spread as an ornamental plant up to Northern Europe. Heracleum genus has 10 species in Iran (Asgarpanah et al., 2012).

The ripe fruits, leaves and young stems of Heracleum persicum are used as antiseptic, carminative, digestive and analgesia as well as flavoring in the Iranian folk medicine (Torbati et al., 2014). Also it has recently been shown to have antioxidant, anticonvulsant, anti-inflammatory and immunemodulatory activities (Asgarpanah et al., 2012).

\footnotetext{
*Correspondence: M. Gharachorloo. Faculty of Food Science and Technology, Science and Reserch Branch, Islamic Azad University, Hesarak, Ashrafi Esfahani, Postal code: 1477893855 - Poonak, Tehran, Iran. E-mail: gharachorlo_m@yahoo.com
}

Among different methods for extraction of essential oils from spices, hydrodistillation is the common and most frequently used method (Morsy, 2015). However, in order to reduce the extraction time, the operation costs, possibly improve the yield and the quality of the essential oils, new approaches such as microwave-assisted extraction, supercritical fluid extraction and ultrasound-assisted extraction have also been in consideration (Memarzadeh, Ghasemi Pirbalouti, Adibnejad, 2015).

In this regards some advances in using microwave have resulted in a number of techniques such as microwave steam diffusion (Farhat et al., 2011), microwave hydrodiffusion and gravity (Vian et al., 2008), microwave dry distillation (Tigrine Korjani, Meklati, Chemat, 2006) and solvent free microwave extraction (Lucchesi et al., 2007). Some recently studies (Golmakani, Rezaei, 2008; Perino Issartier et al., 2013; Stashenko, Jaramillo, Martinez, 2004; Tigrine Kordjani, Meklati, Chemat, 2006) have successfully utilized a microwave oven for the extraction of active components from medicinal plants. 
Therefore the aim of this research was the comparison of the chemical compositions and antioxidant activity of Heracleum persicum essential oil extracted by conventional hydrodistillation (HD) and microwaveassisted hydrodistillation (MAHD) techniques.

\section{MATERIALS AND METHODS}

\section{Material}

Dried aerial parts of Heracleum persicum a spice widely used in Iran were supplied from Tehran market. The identity of the Heracleum was certificated by top experts from Herbarium of the Islamic Azad University, Science and Research Branch. Aerial parts of Heracleum persicum were ground in a mill (Triplex, France), passed through a sieve of $0.5 \mathrm{~mm}$ mesh and the powder obtained was stored in plastic bags, in darkness at $4{ }^{\circ} \mathrm{C}$. Refined sunflower seed oil without added synthetic antioxidant was purchased from Behshahr Oil Company of Tehran. All the chemicals used were of analytical grade, purchased from Merck Chemical Company of Germany.

\section{Isolation of essential oil}

\section{Hydrodistillation}

Powder of aerial parts of Heracleum persicum were hydrodistillated for $3 \mathrm{~h}$ using a Clevenger-type apparatus according to the standard procedure. The essential oil volume was measured directly in the extraction burette. The obtained essential oils were dried with anhydrous sodium sulphate and then stored in a sealed dark vials at $4^{\circ} \mathrm{C}$ until further analysis. Yield percentage was calculated as volume $(\mathrm{mL})$ of essential oil per $100 \mathrm{~g}$ of plant dry matter (Jordán et al., 2009).

\section{Microwave-assisted hydrodistillation (MAHD)}

A domestic microwave oven (micro SYNTH, 2450 $\mathrm{MHz}$ ) was modified for MAHD operation. The interior cavity of the microwave oven was $29 \times 37 \times 40 \mathrm{~cm}$. Flat bottom flask having a capacity of $500 \mathrm{~mL}$ was placed inside the cavity for the MAHD experiments. $20 \mathrm{gr}$ of powdered samples soaked in $100 \mathrm{~mL}$ of distilled water for 30 minutes were placed in a $500 \mathrm{~mL}$ flask. The flask was setup within the microwave oven cavity and a condenser was used on the top, outside the oven. The microwave oven was operated at 600 power level for a period of $30 \mathrm{~min}$ which no more essential oil was obtained. The extracted essential oils were collected, dehydrated with anhydrous sodium sulfate and kept in a sealed dark vials at $4{ }^{\circ} \mathrm{C}$ (Karakaya et al., 2014).

\section{Chemical composition of essential oils}

The chemical compositions of essential oils obtained from aerial parts of Heracleum persicum by using hydrodistillation and microwave-assisted hydrodistillation methods were identified by the application of gas chromatography/mass spectrometry (GC/MS). Samples were analyzed by using an Agilent Hp-6890 gas chromatograph (Agilent Technologies, USA) with a Hp-1 Methyl silicone capillary column (60 $\mathrm{m} \times 0.32 \mathrm{~mm} \times 0.25 \mu \mathrm{m}$ film thickness) linked to Hp-5973 mass spectrometry detector. Oven temperature was set as $60{ }^{\circ} \mathrm{C}$ for $3 \mathrm{~min}$ initially and increased to $230^{\circ} \mathrm{C}$, at a rate of $7{ }^{\circ} \mathrm{C} / \mathrm{min}$ and subsequently held isothermal for $3 \mathrm{~min}$. Injector temperature was set as $250^{\circ} \mathrm{C}$. Helium was used as carrier gas at a flow rate of $1 \mathrm{~mL} / \mathrm{min}$ and $1 \mu \mathrm{L}$ sample was injected manually in the split mode. Ionization of sample compounds was performed in the ET mode $(70 \mathrm{ev})$. The identification of compounds was performed by comparison of their mass spectral pattern and their linear retention indices based on a homologous series of normal alkanes (C8-C20) with those of authentic references and the Wiley 257 mass spectra database.

\section{Antioxidant activity}

\section{$\mathrm{DPPH}$ free radical scavenging assay}

The free radical scavenging activities of essential oils were measured using 1,1-diphenyl-2-picrylhydrazyl (DPPH) as described by El Ouariachi et al. (2014). Antioxidants react with the stable free radical DPPH (deep violet color) and convert it to 1,1-diphenyl2 -picrylhydrazine with discoloration. Various concentrations of essential oils were added to DPPH radical solution in ethanol. The mixture was strongly shaken and left to stand at room temperature for $30 \mathrm{~min}$ in the dark. The absorbance was measured at $517 \mathrm{~nm}$ by using a spectrophotometer (Cary 50 Scan UV-Visible Spectrophotometer). The radical scavenging activity was expressed as percentage of inhibition (I\%) according to the following equation:

$$
\mathrm{I}(\%)=\left[1-\left(\mathrm{A}_{\text {sample }} / \mathrm{A}_{\text {control }}\right)\right] \times 100
$$

where $\mathrm{A}_{\text {control }}$ is the absorbance of the control reaction and $\mathrm{A}_{\text {sample }}$ is the absorbance of the test compound.

The sample concentration providing 50\% inhibition $\left(\mathrm{IC}_{50}\right)$ was calculated from the graph of inhibition percentage against sample concentration. Tests were carried out in triplicate. Ascorbic acid was used as a positive control. 


\section{Oven test method}

The essential oil extracted by MAHD method was added to $100 \mathrm{~g}$ sunflower seed oil at the concentrations of $0.02,0.04,0.06,0.08$ and $0.1 \%(\mathrm{w} / \mathrm{w})$ to examine their antioxidant activity. The antioxidant activity of extracts was compared with tertiary butylhydroquinone (TBHQ) at the concentration of $0.01 \%(\mathrm{w} / \mathrm{w})$. All the samples were placed in the oven at $90{ }^{\circ} \mathrm{C}$ and the peroxide values were determined every $24,48,72$ and $96 \mathrm{~h}$ according to AOCS method, Cd 8-53 by dissolving oil in 3:2 acetic acid-chloroform solution and titration with $0.01 \mathrm{~N}$ sodium thiosulfate solution in the presence of potassium iodide and starch indicator (Firestone, 1994).

\section{Statistical Analysis}

All the experiments and measurements were carried out in triplicate order. The data were statistically analyzed using SPSS 12.0 (SPSS Inc., Chicago, IL, USA). Analyses of variance were performed by application of the ANOVA procedure. Significant differences between the means were determined using Duncan's multiple range test.

\section{RESULTS AND DISCUSSION}

The essential oil extraction by MAHD method started at much earlier time than HD method (5min and 35 min respectively). The process continued until no more essential oil was obtained. Full extraction of essential oils was achieved within the first 30 min of operation with MAHD method. In the case of HD method, a time period of at least $3 \mathrm{~h}$ was necessary for such purpose.

It seems that it is due to the more efficient heat flow involved with microwaves. Unlike the classical conductive heating method, microwave can heat the entire sample almost simultaneously and at a higher rate (Golmakani, Rezaei, 2008).

The results indicated that the yield of essential oil extracted by MAHD $(2.0 \%, \mathrm{v} / \mathrm{w})$ in shorter time of operation was greater than that obtained by $\operatorname{HD}(1.7 \%, \mathrm{v} / \mathrm{w})$ that means a substantial saving in time and operating cost.

Chemical compositions of the essential oils extracted by both MAHD and HD methods are presented in Table I.

Twenty constituents were identified by GC/MS of essential oil isolated by HD method that the predominant compounds were hexyl butanoate $(28.32 \%)$, heptyl isobutanoate (24.05\%), hexyl 2-methylbutanoate (8.24\%), phenyl ethyl 3-methyl butanoate (5.41\%), hexyl acetate (4.47\%), isopropyl-3-methyl butyrate (2.91\%), $\gamma$-terpinene (2.90\%), octenol butanoate (2.87\%), isopropyl-2-methyl butyrate $(2.66 \%)$ and cymene $(2.38 \%)$, accounted for $84.21 \%$ of the essential oil.

TABLE I - Chemical compositions of Heracleum persicum essential oils extracted by MAHD and HD methods

\begin{tabular}{|c|c|c|c|}
\hline \multirow{3}{*}{ Composition } & \multicolumn{3}{|c|}{ Method } \\
\hline & \multicolumn{2}{|c|}{ HD } & \multirow{2}{*}{$\begin{array}{c}\text { MAHD } \\
\text { Amount } \\
(\%)\end{array}$} \\
\hline & $\begin{array}{c}\text { KI } \\
\text { (Kovats Index) }\end{array}$ & $\begin{array}{c}\text { Amount } \\
(\%)\end{array}$ & \\
\hline Cyclohexene & 831 & 0.28 & 8.99 \\
\hline Methyl pentanoate & 877 & 0.43 & - \\
\hline Isopropyl-2-methyl butyrate & 885 & 2.66 & - \\
\hline Isopropyl-3-methyl butyrate & 901 & 2.91 & - \\
\hline Butyl butanoate & 994 & 0.42 & - \\
\hline Octanal & 998 & 0.41 & 3.79 \\
\hline Penthyl propanoate & 1007 & 0.57 & - \\
\hline Isoamyl isobutyrate & 1009 & 4.47 & - \\
\hline Cymene & 1026 & 2.38 & - \\
\hline Limonene & 1029 & 1.02 & - \\
\hline Terpinene $(\gamma)$ & 1059 & 2.90 & - \\
\hline Hexyl butanoate & 1192 & 28.32 & - \\
\hline Caranone & 1200 & 0.73 & - \\
\hline Hexyl 2- Methyl butanoate & 1236 & 8.24 & 1.52 \\
\hline Heptyl isobutanoate & 1250 & 24.05 & 78.50 \\
\hline Anethole & 1284 & 0.41 & - \\
\hline Octenol butanoate & 1388 & 2.87 & 1.36 \\
\hline Menthyl lactate & 1469 & 0.50 & 1.98 \\
\hline Phenyl ethyl 3-methyl butanoate & 1491 & 5.41 & 2.06 \\
\hline Cedrene-3-one & 1645 & 0.24 & - \\
\hline
\end{tabular}


The results indicated that the main constituents of the essential oil extracted by MAHD method were heptyl isobutanoate $(78.50 \%)$, cyclohexene $(8.99 \%)$, octanal (3.79\%), phenyl ethyl 3-methyl butanoate $(2.01 \%)$.

Although the main compounds of essential oils extracted by the both extraction methods were similar, essential oil extracted by HD with lower extraction efficiency showed more diverse compounds that might be due to the formation of new compounds by oxidation, glycoside hydrolysis, esterification and other processes in the longer time of extraction (Ghasemi Pirbalouti, Mahdad, Craker, 2013), also it means that the MAHD method is more selective than conventional hydrodistillation because does not involve in any deterioration of the extracted components and minimizes the risk of compound degradation due to the extraction rate (Memarzadeh, Ghasemi Pirbalouti, Adibnejad, 2015), therefore it might be introduced as a safe method for the extraction of essential oils.
Various techniques are available to evaluate the antioxidant activity of specific compounds or complex mixtures such as essential oils; however a single procedure cannot identify all possible mechanisms characterizing an antioxidant (Nikolic et al., 2013). Therefore, in the present study, two different methods were conducted in order to evaluate the antioxidant activities of Heracleum persicum essential oil; DPPH free radical scavenging assay and oil stability by the oven test method.

The results of DPPH radical-scavenging activity assay (Figure 1) indicated that the percentage of inhibition increased with increasing of essential oil concentration and $\mathrm{IC}_{50}$ values for essential oils extracted by HD and MAHD methods were obtained $1.43 \mathrm{mg} / \mathrm{mL}$ and $1.25 \mathrm{mg} / \mathrm{mL}$ respectively which is weaker than that reported by Coruh, Sagdicoglu and Ozgokce (2007).

Due to the extraction rate, efficiency, $\mathrm{IC}_{50}$ value and chemical composition of the essential oil obtained by
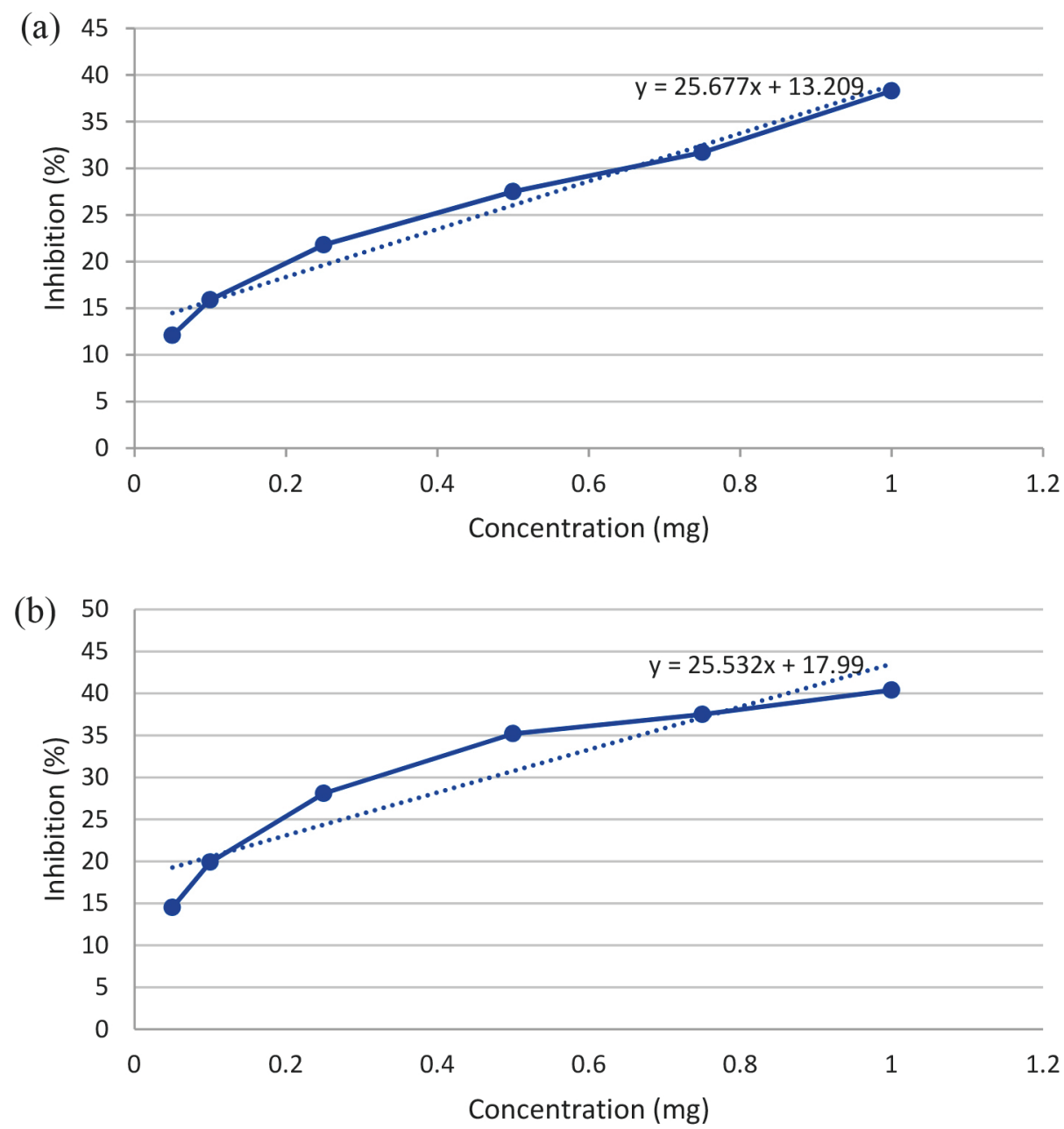

FIGURE 1 - DPPH radical scavenging activity; (a) essential oil extracted by HD method, (b) essential oil extracted by MAHD method. $\mathrm{IC}_{50}$ value for Ascorbic acid as control was obtained $0.06 \mathrm{mg} / \mathrm{mL}$. 
TABLE II - Peroxide values of sunflower seed oil with different concentrations of Heracleum persicum essential oil at $90^{\circ} \mathrm{C}$ (meq/ $\mathrm{kg}$ oil)*

\begin{tabular}{lccccc}
\hline Treatment & \multicolumn{5}{c}{ Time of heating } \\
\cline { 2 - 6 } & $0 \mathrm{~h}$ & $24 \mathrm{~h}$ & $48 \mathrm{~h}$ & $72 \mathrm{~h}$ & $96 \mathrm{~h}$ \\
\hline Control & $0.05 \pm 0.00$ & $17.91 \pm 0.02^{\mathrm{a}}$ & $39.12 \pm 0.05^{\mathrm{a}}$ & $61.82 \pm 0.10^{\mathrm{a}}$ & $79.84 \pm 0.03^{\mathrm{a}}$ \\
TBHQ $(0.01 \%)$ & $0.05 \pm 0.00$ & $3.00 \pm 0.05^{\mathrm{g}}$ & $7.11 \pm 0.08^{\mathrm{g}}$ & $16.56 \pm 0.05^{\mathrm{g}}$ & $29.00 \pm 0.05^{\mathrm{g}}$ \\
MAHD $(0.02 \%)$ & $0.05 \pm 0.00$ & $16.91 \pm 0.00^{\mathrm{b}}$ & $32.00 \pm 0.01^{\mathrm{b}}$ & $47.86 \pm 0.01^{\mathrm{b}}$ & $66.61 \pm 0.07^{\mathrm{b}}$ \\
MAHD $(0.04 \%)$ & $0.05 \pm 0.00$ & $13.86 \pm 0.07^{\mathrm{c}}$ & $29.97 \pm 0.00^{\mathrm{c}}$ & $44.50 \pm 0.03^{\mathrm{c}}$ & $57.21 \pm 0.03^{\mathrm{c}}$ \\
MAHD $(0.06 \%)$ & $0.05 \pm 0.00$ & $10.97 \pm 0.24^{\mathrm{f}}$ & $27.36 \pm 0.00^{\mathrm{d}}$ & $33.81 \pm 0.12^{\mathrm{d}}$ & $48.07 \pm 0.00^{\mathrm{d}}$ \\
MAHD $(0.08 \%)$ & $0.05 \pm 0.00$ & $11.40 \pm 0.16^{\mathrm{e}}$ & $25.90 \pm 0.05^{\mathrm{e}}$ & $28.54 \pm 0.05^{\mathrm{f}}$ & $46.53 \pm 0.14^{\mathrm{e}}$ \\
MAHD $(0.10 \%)$ & $0.05 \pm 0.00$ & $11.92 \pm 0.08^{\mathrm{d}}$ & $24.03 \pm 0.02^{\mathrm{f}}$ & $29.73 \pm 0.05^{\mathrm{e}}$ & $42.66 \pm 0.01^{\mathrm{f}}$ \\
\hline
\end{tabular}

$*$ The values are expressed as means \pm standard deviation, $\mathrm{n}=3$. Different letters in each column indicate significant differences $(\mathrm{P}<0.05)$.

MAHD method, oven test method was only carried out on this essential oil.

The effect of Heracleum persicum essential oil and TBHQ on sunflower seed oil oxidation are shown in Table II. Peroxide value of fresh sunflower oil was $0.05 \mathrm{meq} / \mathrm{kg}$, which has increased as the result of oxidation. Sunflower oil with added TBHQ showed the lowest peroxide value after $96 \mathrm{~h}$ at $90^{\circ} \mathrm{C}$ as compared with other treatments, which might be due to the fact that TBHQ is a potent antioxidant particularly at accelerated oven test which is carried out at high temperature.

The results shown in Table II indicate that all used concentrations of essential oil decreased the rate of oxidation of sunflower oil and significant differences were found between all treatments $(\mathrm{p}<0.05)$. The evaluation of antioxidant activity of the essential oil measured by delay in sunflower oil oxidation also indicated that the antioxidant activity was dependent on the concentration which increased when higher concentrations of the essential oils were applied. Increasing the concentration of Heracleum persicum essential oil showed lower rate of oxidation and consequently lower peroxide values were obtained. The results indicated that the greatest increase in stability was obtained when sunflower oil treated with $0.1 \%(\mathrm{~V} / \mathrm{W})$ concentration of essential oil.

The limitations of this study include collecting plants due to its diversity, the possibility of contamination with pesticide and its toxicity.

The Heracleum persicum essential oil might be recommended for use as a flavoring agent and a source of natural antioxidants in functional foods, formulation of the supplements and in medicinal due to numerous pharmacological activities.

\section{REFERENCES}

Asgarpanah J, Dadashzadeh Mehrabani G, Ahmadi M, Ranjbar R, Safi-Aldin Ardebily M. Chemistry, pharmacology and medicinal properties of Heracleum persicum Desf. Ex Fischer: a review. J Med Plants Res. 2012;6(10):1813-20.

Coruh N, Sagdicoglu CAG, Ozgokce F. Antioxidant properties of Prangos frulacea (L.), Chaerophyllum macropodum Boiss. and Heracleum persicum Desf. from Apiaceae family usedas food in Eastern Anatolia and their inhibitory effects on glutathione-stransferase. Food Chem. 2007;100(3):1237-42.

El Ouariachi EM, Hamdani I, Bouyanzer A, Hammouti B, Majidi L, Costa J, et al. Chemical composition and antioxidant activity of essential oils of Thymus broussonetii Boiss. and Thymus algeriensis Boiss. from Morocco. Asian Pac J Trop Dis. 2014;4(4):281-6.

Farhat A, Fabiano Tixier AS, Maataoui M, Maigonnat JF, Romdhane M, Chemat F. Microwave steam diffusion for extraction of essential oil from orange peel: kinetic data, extract's global yield and mechanism. Food Chem. 2011;125(1):255-61.

Firestone D. Official methods and recommended practices of the American Oil Chemists' Society. 4th edn. Boulder, Urbana: AOCS Press; 1994. 2 v.

Ghasemi Pirbalouti A, Mahdad E, Craker L. Effects of drying methods on qualitative and quantitative properties of essential oil of two basil landraces. Food Chem. 2013;144(3):2440-9. 
Golmakani MT, Rezaei K. Comparison of microwave-assisted hydrodistillation with traditional hydrodistillation method in the extraction of essential oils from thymus vulgaris L. Food Chem. 2008;109(4):925-30.

Jordán MJ, Martínez RM, Martínez C, Monino I, Sotomayor JA. Polyphenolic extract and essential oil quality of Thymus zygis ssp. gracilis shrubs cultivated under different watering levels. Ind Crop Prod. 2009;29(1):145-53.

Karakaya S, Nehir El S, Karagozlu N, Sahin S, Sumnu G, Bayramoglu B. Microwave-assisted hydrodistillation of essential oil from rosemary. J Food Sci Technol. 2014;51(6):1056-65.

Lucchesi ME, Smadja J, Bradshaw S, Louw W, Chemat F. Solvent free microwave extraction of Elletaria cardamomum L.: a multivariate study of a new technique for the extraction of essential oil. J Food Eng. 2007;79(3):1079-86.

Memarzadeh SM, Ghasemi pirbalouti A, Adibnejad M. Chemical composition and yield of essential oils from Bakhtiari savory (Satureja bachtiarica bunge) Under different extraction methods. Ind Crop Prod. 2015;76:809-16.

Morsy NFS. A short extraction time of high quality hydrodistillation cardamom (Elettaria cardamomum L. Maton) essential oil using ultrasound as a pretreatment. Ind Crop Prod. 2015;65:287-92.
Nikolic M, Glamoclija J, Ferreira IC, Callhelha R, Fernndes A, Markovic T, Markovic D, Giweli A, Sokovic M. Chemical composition, antimicrobial, antioxidant and antitumor activity of thymus serpyllum L., thymus algeriensis Boiss and Reut and thymus vulgaris L. essential oils. Ind Crop Prod. 2013;52:183-90.

Perino Issartier S, Ginies C, Cravotto G, Chemat F. A comparison of essential oils obtained from lavandian via different extraction processes: Ultrasound, microwave, turbo hydrodistillation, steam and hydrodistillation. J Chromatogr A. 2013;1305:41-7.

Stashenko EE, Jaramillo BF, Martinez JR. Comparison of different extraction methods for the analysis of volatile secondary metabolites of lippa alba (Mill). NE Brown, grown in Colombia and evaluation of its in vitro antioxidant activity. $\mathrm{J}$ Chromatogr A. 2004;1025(1):93-103.

Tigrine Kordjani N, Meklati B, Chemat F. Microwave 'dry' distillation as an useful tool for extraction of edible essential oils. Int J Aromatherapy. 2006;16(3-4):141-7.

Torbati M, Nazemiyeh H, Lotfipour F, Nemati M, Asnaashari $\mathrm{S}$, Fathizad F. Chemical composition and in vitro antioxidant and antibacterial activity of Heracleum anisactis roots essential oils. Bioimpacts. 2014;4(2):69-74.

Vian MA, Fernandez X, Visinoni F, Chemat F. Microwave hydrodiffusion and gravity, a new technique for extraction of essential oils. J Chromatogr A. 2008;1190(1-2):14-17.

Received for publication on $03^{\text {rd }}$ January 2017 Accepted for publication on $04^{\text {th }}$ March 2017 